ager, commented, "Through the success of its Second National Conference ACRL has shown once again that ALA divisional membership can meet in a non-business forum to discuss in detail the pressing professional issues of the day. By meeting in Minneapolis, ACRL has continued to provide its members around the country with quality programming and an opportunity for professional socialization and development."

Looking towards the Third National Conference on April 4-7, 1984, in Seattle, ACRL will bring to the country's western regions what it already has to members in the midwest and east. We hope you will join us as we anticipate 1984.

\section{CE COURSE REPORT}

"A very stimulating presentation and an excellent example of teaching."

"Very good, brilliant and conscientious instructors."

"A most informative and extremely timely experience for me."

"4 stars! Superiort."

The preceding remarks, taken from course evaluations, are typical of the overwhelmingly positive response to the eight continuing education courses offered by ACRL on September 29-October I, prior to the National Conference in Minneapolis. Approximately 114 academic and public librarians enrolled in the courses, which ranged in length from one to three days. Many of the participants took advantage of the scheduling opportunities, enrolling in two courses.

"Effective Supervisory Skills" taught by Herbert S. White, of Indiana University, provided an introduction to techniques for effective supervision such as evaluating progress, determining and scheduling completion dates, and maintaining an interim report system. White's lively presentation was enthusiastically received by course participants.

Suzanne H. Mahmoodi of the Office of Public Libraries and Interlibrary Cooperation for the State of Minnesota presented a general background in basic principles and research findings in group behavior in "Working Effectively with Groups." The course was structured around active group work, allowing participants firsthand experience in group dynamics.

Administrators of small and medium-sized academic libraries received information regarding managerial considerations essential in establishing the successful bibliographic instruction program. Taught by Dennis E. Robinson, University of Richmond, "Establishing the College Bibliographic Instruction Program: The Director's Role" examined political aspects as well as the staff, budgetary, faculty, and administrative support necessary for establishing a workable BI program.
"An Introduction to Maps in Libraries: Maps as Information Tools" provided for the nonspecialist an explanation of the information potential of maps in the library environment. Charles Seavey (University of New Mexico) and David Cobb (University of Illinois) used a number of effective instructional approaches to illustrate the role of maps in acquisitions, collection development, reference, and instruction, as well as the space and equipment requirements of maps.

The most popular of the courses was "Teaching Methods for the Bibliographic Instruction Librarian." Marilla Svinicki of the University of Texas at Austin's Center for Teaching Effectiveness involved the 34 participants in a number of creative exercises illustrating a basic review and practice in learning theory and instructional methods particularly effective in the bibliographic instruction situation.

Richard W. Boss, Senior Consultant for Information Systems Consultants, Inc., Bethesda, Maryland, supplied participants in his course, "Management Issues in Automation and Information Technology," with an overview of library and information technology. He emphasized administrative, economic, political, and other nontechnical aspects of selecting, procuring and using these technologies.

Participants in "Writing the Journal Article and Getting it Published" received an overview of the publishing process. Instructor Richard D. Johnson of SUNY-Oneonta covered such topics as selection of a publishing medium, preparation of the manuscript, submission of the manuscript, and pre- and post-publication matters and helped participants devise an effective strategy for publishing their work.

Keith W. Russell, Council on Library Resources, led an enthusiastic group through a number of practical self-assessment and jobhunting techniques relevant to career development and growth in the academic library environment in his course, "Career Advancement in Academic Librarianship: Techniques for Upward Mobility." Small-group activities and creative exercises highlighted this carefully planned course.

Three ACRL-owned CE courses made their debut in Minneapolis. Materials can be purchased from ACRL Headquarters for "Establishing the College Bibliographic Instruction Program: The Director's Role," "Teaching Methods for the Bibliographic Instruction Librarian," and "Writing the Journal Article and Getting it Published" (\$15 for members, \$20 for non-members).

In addition to course content, participants were pleased by the size of the courses, which were small enough to allow for maximum interaction between instructors and students. Participants were given the opportunity to suggest ideas for future ACRL courses.-C. Brigid Welch. 